\title{
Linking Lipids to Alzheimer's Disease: Cholesterol and Beyond
}

\author{
Gilbert Di Paolo and Tae-Wan Kim \\ Department of Pathology and Cell Biology, Taub Institute for Research on Alzheimer's Disease \\ and the Aging Brain, Columbia University Medical Center, New York, NY 10032, USA
}

\section{Abstract}

Lipid-mediated signaling regulates a plethora of physiological processes, including critical aspects of brain function. In addition, dysregulation of lipid pathways has been implicated in a growing number of neurodegenerative disorders, such as Alzheimer's disease (AD). Although much attention has been given to the link between cholesterol and $\mathrm{AD}$ pathogenesis, growing evidence suggests that other lipids, such as phosphoinositides, play an important role. Because regulators of lipid metabolism (e.g. statins) are a highly successful class of marketed drugs, exploration of lipid dysregulation in $\mathrm{AD}$ and identification of novel therapeutic agents acting through relevant lipid pathways offers new and effective options for the treatment of this devastating disorder.

\begin{abstract}
Alzheimer's disease (AD) is a fatal neurodegenerative disease characterized clinically by progressive memory loss as well as aberrant behavior ${ }^{1,2}$, which, in the majority of cases occurs late in life and without a known cause (sporadic Alzheimer's disease, SAD). Patients with AD display loss of synapses and neurons, as well as extracellular senile plaques and intracellular neurofibrillary tangles (NFTs). Senile plaques consist largely of aggregated amyloid $\beta$-peptide $(A \beta)$, which is liberated from the holoprotein, amyloid precursor protein (APP), by sequential cleavages mediated by the $\beta$-secretase Beta-site APP cleavage enzyme 1 (BACE1) and the $\gamma$-secretase complex ${ }^{1,2}$ (Box 1). Rare but highly penetrant mutations in the genes encoding APP and presenilins 1 and 2, the catalytic components of the $\gamma$-secretase, result in early-onset familial AD (FAD). Intraneuronal accumulation of insoluble aggregates of tau in the form of NFTs is also a pathological hallmark of $\mathrm{AD}^{3}$. While under normal conditions tau binds and stabilizes microtubules in axons, a plethora of studies indicate that under pathological conditions, tau becomes hyperphosphorylated. This phenomenon causes the detachment of tau from microtubules and promotes the formation of insoluble tau aggregates, thus leading to the occurrence of paired helical filaments and NFTs present in $\mathrm{AD}$ brains ${ }^{3}$. Although $\mathrm{AD}$-associated cognitive dysfunction is shown to correlate strongly with the accumulation of $A \beta$ and the severity of tau pathology, the precise relationship between these two pathological AD hallmarks remains poorly understood, particularly in $\mathrm{SAD}^{4}$.
\end{abstract}

\begin{abstract}
Alois Alzheimer originally described a third pathological hallmark of $\mathrm{AD}$, which was largely ignored by scientists in the field at its infancy, perhaps due to the lack of appropriate analytical tools. Indeed, AD brain displays a higher occurrence of "adipose inclusions" or "lipoid granules", suggesting aberrant lipid metabolism 5 . Subsequently, biochemical alterations of lipid composition have been reported in post mortem brain tissue derived from individuals with AD. However, an intimate link between lipid metabolism and AD was only
\end{abstract}

Correspondence should be addressed to G.D.P. (gil.dipaolo@columbia.edu) or T.-W.K (twk16@ columbia.edu).

Dr. Gilbert Di Paolo, Columbia University Medical Center, Department of Pathology and Cell Biology, Taub Institute for Research on Alzheimer's Disease and the Aging Brain, 630 West $168^{\text {th }}$ Street, P\&S 12-420C, New York, NY 10032, Phone: +1-212-304-5500 Dr. Tae-Wan Kim, Columbia University Medical Center, Department of Pathology and Cell Biology, Taub Institute for Research on Alzheimer's Disease and the Aging Brain, 630 West $168^{\text {th }}$ Street, P\&S 12-420E, New York, NY 10032, Phone: $+1-212-305-5786$ 
established when the $\varepsilon 4$ allele of the apolipoprotein E (APOE) gene was identified as the strongest genetic risk factor for $\mathrm{SAD}^{6,7}$. ApoE encodes a $\sim 34 \mathrm{kDa}$ protein that serves as a crucial regulator of cholesterol metabolism in the brain and triglyceride metabolism throughout the body. It mediates the uptake of lipoprotein particles in the brain via the lowdensity lipoprotein receptor related protein (LRP) and the very low-density family lipoprotein receptor [recently reviewed by reference 8 and 9] (Fig. 1). The role of ApoE4 in amyloid pathology is supported by evidence that it binds $A \beta$ and modulates the aggregation and clearance of $A \beta$. Additionally, several epidemiological studies now support a role for cholesterol in the pathogenesis of $\mathrm{AD}^{8,9}$.

It is now well established that most, if not all, classes of lipids are implicated in AD pathogenesis, which can be reconciled with the following facts. First, lipids regulate the trafficking and/or proteolytic activity of membrane-bound proteins which play a fundamental role in this disorder, including APP, BACE1 and presenilins. Second, cytotoxic entities responsible for key phenotypic manifestations of $A D$, such as $A \beta$, exert their effects primarily by perturbing cellular membranes through direct and indirect mechanisms. Third, lipids themselves modulate the pathogenic potential of $A \beta$ and perhaps tau as well, by affecting their propensity to aggregate. Thus, the scope of this review is to address the role of lipid dyshomeostasis in either mediating or modulating key pathological processes associated with AD. Specifically, this review elaborates on the roles of cellular lipids in the production and aggregation of $\mathrm{A} \beta$, in mediating $\mathrm{AD}$-associated synaptic dysfunction and in tau pathology.

\section{Regulation of amyloidogenesis by lipids}

APP, BACE1 and the components of the $\gamma$-secretase complex are transmembrane proteins. Consequently, lipid bilayer composition and organization have a significant impact on trafficking properties, as well as the proteolytic activities of $\beta$ - and $\gamma$-secretases ${ }^{10}$. Here, the role of cholesterol and other membrane lipid families in APP metabolism and secretase activity will be reviewed.

\section{Role of cholesterol metabolism and transport in amyloidogenesis}

In the brain, cholesterol is present mainly in its unesterified form in myelin sheaths and the cellular membranes of glial cells and neurons ${ }^{11}$. Within the cells, the biggest reservoirs of cholesterol are found at the plasma membrane as well as in the endocytic recycling compartment ${ }^{12}$. Since the blood brain barrier prevents any efficient exchange between brain and plasma lipoproteins, the majority of brain cholesterol is derived from de novo biosynthesis, rather than acquiring it from plasma LDL (Fig. 1) ${ }^{11,13}$. Excess free cholesterol in the cell is converted into cholesteryl-esters by the enzyme acyl-coenzymeA:cholesterol acyltransferase (ACAT) (Fig. 1; Suppl. Fig. 1b), followed by accumulation in intracellular lipid droplets or efflux through the plasma membrane into the extracellular environment ${ }^{14}$. Increasing levels of cholesteryl-esters enhances $\mathrm{A} \beta$ release in cultured cells, while pharmacological inhibition of ACAT (e.g., using CP-113818) leads to the reduction of both $\mathrm{A} \beta$ and cholesteryl-ester ${ }^{15-17}$ (Fig. 1). Genetic ablation of ACAT1 reduces both A $\beta$ pathology and cognitive impairments in a mouse model of $\mathrm{AD}^{18}$. However, complicating the interpretation, ACAT1 ablation also increases levels of oxysterol, 24(S)-hydroxy cholesterol (Suppl. Fig. 1c), suggesting a potential role of this cholesterol metabolite in decreasing amyloidogenesis 16,18 . One putative mechanism consistent with these results is that the excess free brain cholesterol resulting from ACAT1 ablation, can be converted into 24(S)hydroxycholesterol and subsequently cross the blood-brain barrier to reach the periphery, thus leading to reduced brain cholesterol levels. Together, these data suggest that the balance between free cholesterol and cholesterol esters is a key parameter controlling amyloidogenesis, although the molecular basis underlying this relationship is unclear ${ }^{16}$. 
Several lines of evidence indicate that cholesterol efflux also controls $\mathrm{A} \beta$ generation (Fig. 1). ATP-binding cassette transporter A1 (ABCA1) serves as an important regulator of the levels and lipidation status of ApoE by stimulating efflux of excess intracellular cholesterol to extracellular lipid acceptors, including unlipidated $\mathrm{ApoE}^{19,20}$. Increased levels of $\mathrm{ABCA} 1$ were found to lower $\mathrm{A} \beta$ levels in cultured cells ${ }^{21}$. Conversely, in vivo studies showed that deletion of ABCA1 gene in mouse models of AD dramatically decreases the levels of $A p o E$ both in the brain and in the periphery, which correlates with greater $A \beta$ deposits 22-24. Because residual ApoE in ABCA1-deficient mice is poorly lipidated, it was speculated that the low levels of ApoE lipidation, rather than the low levels of ApoE per se, promote amyloidogenesis ${ }^{19}$. Alternatively, the latter phenomenon may be accounted for by accumulation of intracellular cholesterol as a result of decreased efflux ${ }^{19}$.

\section{Role of cellular cholesterol and lipid rafts in amyloidogenesis}

Cholesterol can also directly modulate secretase activities leading to altered $\mathrm{A} \beta$ generation (Fig. 2). Reducing membrane cholesterol levels via cholesterol-extracting compounds, such as beta-methyl-cyclodextrin ( $\beta \mathrm{MCD})$, decreases activity of both BACE1 and $\gamma$-secretase, leading to an additive reduction in $A \beta$ generation ${ }^{10,25,26}$. Additionally, cell-free assays indicate that high cholesterol content directly influences the activity of recombinant BACE1 in reconstituted unilamellar vesicles ${ }^{27}$ (Fig. 2a,c). Treatment of cholesterol-enriched vesicles containing BACE1 with $\beta M C D$ reduces the amount of membrane-associated BACE1, suggesting that cholesterol-enriched microenvironments could directly influence the activity of BACE1. Cholesterol levels also directly regulate $\gamma$-secretase-mediated production of $\mathrm{A} \beta$ (Fig. $2 \mathrm{c}$ ) ${ }^{25,28,29}$. Inclusion of cholesterol or sphingolipids in PCcontaining vesicles leads to increased $\gamma$-secretase activity 30,31 . Together, these in vitro data are consistent with a role of cholesterol- and sphingolipid-enriched membrane microdomains called "lipid rafts" (Box 2) in the amyloidogenic processing of APP.

Despite the fact that pools of APP, BACE1 and presenilin are present in both raft and nonraft regions of the membranes, APP processing occurring within lipid rafts appears to be largely amyloidogenic, while outside lipid rafts, APP is processed predominantly by the non-amyloidogenic, $\alpha$-secretase pathway (Fig. 2) ${ }^{1,2,26}$. A significant pool of BACE1 is localized to lipid rafts ${ }^{32,33}$ mainly through palmitoylation of its transmembrane and cytoplasmic domains ${ }^{34,35}$. Cholesterol depletion decreases the association of BACE1 with lipid rafts, which correlates with decreased amyloidogenic processing of APP (Fig.

2a) $32,33,36$. In contrast, acute cell exposure to cholesterol promotes the co-clustering of APP and BACE1 in lipid raft domains and their rapid endocytosis ${ }^{37}$. Further supporting the key role of the BACE1-raft association in $\mathrm{A} \beta$ generation, introduction of a glycosylphosphatidylinositol (GPI) anchor, a targeting motif for lipid raft localization, into BACE1 sequence strongly promotes amyloidogenic processing of APP ${ }^{26,35}$. Collectively, these studies suggest that cholesterol-sensitive $A \beta$ production is determined, at least in part, by the levels of BACE1 present in lipid rafts. However, there may be cell-type specific differences dictating the extent of this relationship. Enhancing the association of APP with lipid rafts also favors amyloidogenic processing $26,33,38,39$. Finally, core components of the $\gamma$-secretase complex, including presenilins, are also associated with lipid rafts (Fig.

2) $26,29,40$. Accordingly, inhibition of $\gamma$-secretase activity leads to the accumulation of APP $\mathrm{COOH}$-terminal products in lipid rafts (Fig. 2a,c) ${ }^{26}$. In contrast, other $\gamma$-secretase substrates, such as Notch 1 and Jagged 2, are largely processed in non-raft compartments ${ }^{41}$. Collectively, these studies suggest that modulating the biophysical properties of rafts to decrease association of APP, BACE1 or presenilins with these lipid microdomains, may offer a therapeutic opportunity to reduce amyloidogenic processing of APP, thus delaying the progression of $\mathrm{AD}$. 


\section{Role of sphingolipids in $A \beta$ production}

In addition to cholesterol, sphingolipids, including ceramide, sphingomyelin (SM) and glycosphingolipids (GSLs) (Suppl. Fig. 2a), are major components of lipid rafts, playing a number of crucial roles in cell functions associated with normal as well as diseased states ${ }^{42,43}$. Ceramide is a central component in sphingolipid metabolism and serves as the backbone to generate sphingomyelin (SM) or more complex glycosphingolipids (GSLs) via the addition of phosphocholine or sugars at the hydroxyl group, respectively. SM and GSLs are abundant in the brain, and gangliosides, which are GSLs containing sialic acids, are the major components of neuronal membranes (see below). Early reports show that ceramide levels are elevated at the earliest clinically recognizable stage of $\mathrm{AD}$, perhaps mediating oxidative stress-induced neuronal death ${ }^{44}$. However, ceramide also regulates BACE1mediated processing of APP independently of its role in oxidative cell death. The mechanism appears to be related to the enhancement of BACE1 stability in cells, perhaps through the formation of ceramide-enriched platforms (Fig. 2c) ${ }^{45,46}$.

Sphingolipids are also directly involved in APP metabolism. Inhibition of sphingomyelinase (SMase), the enzyme that mediates the conversion of SM to ceramide, and resulting SM accumulation, reduces $A \beta$ secretion due to inhibition of $\gamma$-secretase activity (Fig. $2 \mathrm{c}$ ) ${ }^{47}$. Enhanced SMase activity is also detected in cells harboring FAD mutations in PS1, further indicating an important role for sphingolipids in $\mathrm{AD}^{47}$. However, suppression of the entire sphingolipid biosynthetic pathway by inhibition of serine-palmitoyl-transferase leads to increased $A \beta 42$ production while $A \beta 40$ levels remain unchanged. Subsequent addition of sphingosine restores the normal $\mathrm{A} \beta 42 / \mathrm{A} \beta 40$ ratio indicating sphingolipids may act as $\gamma$ secretase modulators ${ }^{48}$. Finally, the V3 loop-domain of the A $\beta$ peptide has been described as a sphingolipid-binding sequence ${ }^{49}$ and confers affinity for this peptide to raft-like sphingolipid- and cholesterol-rich regions of cellular membranes, with potentially important implications for the aggregation, internalization and intracellular sorting of $A \beta$, all of which can affect its pathogenic potential ${ }^{50}$. Collectively, these studies show that sphingolipids modulate activity of $\gamma$-secretase and BACE1 as well the microdomain localization of A $\beta$, although further work is needed to elucidate the mechanistic details and to validate these lipid-dependent models in vivo.

\section{Isoprenoids and small GTPases}

The HMG-CoA reductase pathway, also called the mevalonate pathway, not only leads to the synthesis of cholesterol, but also provides eukaryotic cells with essential lipids, such as isoprenoids (recently reviewed in ref. ${ }^{51}$ ) (Suppl. Fig. 1a). Thus, statins, which block HMGCoA reductase, may also exert their effects through cholesterol-independent mechanisms ${ }^{52}$. Long-chain isoprenoids play a role in membrane organization and protein glycosylation (e.g., dolichol) as well as mitochondrion respiration (e.g., ubiquinone or coenzyme Q). In contrast, short-chain isoprenoids farnesylpyrophosphate (FPP) and its metabolite geranylgeranylpyrophosphate (GGPP) are utilized for the isoprenylation of a wide variety of proteins, including nuclear lamins and small GTPases of the Ras, Rho and Rab families. Small GTPases act as molecular switches in a myriad of signaling and trafficking pathways and their isoprenylation, referred to as farnesylation and geranylgeranylation, allows for recruitment to the cytosolically-exposed leaflets of cellular membranes, where they exert their signaling actions. Recent evidence suggests that a perturbation of the metabolism of FPP and GGPP and thus GTPase signaling occurs in AD ${ }^{51,53}$. This phenomenon is likely to be relevant for AD pathogenesis because GTPase signaling can control multiple aspects of amyloidogenesis, including the trafficking of APP, BACE1 and $\gamma$-secretase.

While long-chain isoprenoids were reported to be altered in AD brains two decades ago ${ }^{54}$, more recent studies have established that GGPP and to a lesser extent, FPP, are significantly 
elevated in the frontal cortex of $\mathrm{AD}$ patients, consistent with increased levels of their respective synthases 55 . Importantly, pharmacological studies in various model systems, including in mice, have implicated short-chain isoprenoids as primary regulators of APP metabolism. Indeed, a search for the mechanism governing the A $\beta 42$-lowering action of non-steroidal anti-inflammatory drugs (NSAIDs) has identified the activation of small GTPase Rho and its effector Rho-associated kinase (Rock) as potential mediators of this effect ${ }^{56}$, although alternate mechanisms have also been proposed ${ }^{57}$. While isoprenylation has been proposed to modulate the specificity or activity of $\gamma$-secretase in A $\beta 42$ generation $^{40,58}$, statins were shown to promote ectodomain shedding of APP through the $\alpha$ secretase pathway in a cholesterol-independent manner by inhibiting isoprenoid-mediated Rho/ROCK signaling, in favor of the non-amyloidogenic processing of APP (Fig. 2b) ${ }^{59}$. However, lowering isoprenoid levels, yet, maintaining normal cholesterol levels, alters the traffic of APP leading to accumulation of $\beta$ COOH-terminal fragments ( $\beta$ CTFs) and intracellular $A \beta$, suggesting that processing through the $\beta$-secretase pathway is enhanced (Fig. 2c) ${ }^{60}$. Collectively, these studies indicate that isoprenylation differentially modulates all three secretase activities and underscores the pleiotropic effects of statins on APP metabolism by identifying cholesterol-and isoprenoid-specific processes.

\section{Role of phospholipids in $A \beta$ production}

Early studies on AD brain tissue reported alterations of the composition and metabolism of several phospholipids, including phosphoinositides (i.e., phosphorylated derivatives of phosphatidylinositol), as well as changes in the levels of several phospholipid-metabolizing enzymes, such as phospholipases A2 (PLA2), C (PLC) and D (PLD), and phosphoinositide kinases and phosphatases 61,62 . Additionally, wortmannin, a classical inhibitor of the phosphatidylinositol 3-kinase (PI3K) pathway was shown to reduce the levels of A $\beta$ both in vitro and in vivo, thus further highlighting a potential role of phosphoinositides in $\mathrm{AD}$ pathogenesis ${ }^{63,64}$, Phosphatidylinositol-4,5-bisphosphate [PtdIns $(4,5) \mathrm{P}_{2}$ ], the most abundant and best characterized species of phosphoinositides, is predominantly implicated in functions related to the plasma membrane ${ }^{65}$. Insight into its role in amyloidogenesis was provided by the finding that reconstituted $\gamma$-secretase complex activity in liposomes is exquisitely sensitive to the presence of $\operatorname{PtdIns}(4,5) \mathrm{P}_{2}$. This inhibitory effect on APP cleavage was proposed to reflect competitive interference between $\operatorname{Ptd} \operatorname{Ins}(4,5) \mathrm{P}_{2}$ and the substrate for their interaction with the $\gamma$-secretase complex ${ }^{30,31}$. Further studies have shown that cellular PtdIns $(4,5) \mathrm{P}_{2}$ levels inversely correlate with secreted $\mathrm{A} \beta 42$ levels in cultured fibroblasts ${ }^{66}$. The same study showed that enhanced turnover of PtdIns $(4,5) \mathrm{P}_{2}$ through the PLC pathway is a consequence of FAD-associated mutations in the presenilin genes. Reducing PtdIns $(4,5) \mathrm{P}_{2}$ turnover with a PLC inhibitor both decreases $\mathrm{A} \beta 42$ secretion and prevents $\mathrm{Ca}^{2+}$ entry, deficits commonly associated with these mutations (Fig. 2c) 66,67 . While this raises the possibility of therapeutic targeting the PLC pathway, PLC-mediated PtdIns $(4,5) \mathrm{P}_{2}$ hydrolysis produces diacylglycerol, which, in turn, stimulates $\alpha$-secretase via protein kinase C-dependent and independent mechanisms (Fig. 2b) ${ }^{68}$. In the latter context, blocking PLC may thus indirectly enhance amyloidogenesis. Overall, it remains to be seen whether inhibition of PLC would be beneficial or not in AD.

The PLD pathway has also been shown to play a role in amyloidogenesis ${ }^{62}$. Most studies on the link between PLD and amyloidogenesis have so far focused on PLD1, which, like related family member PLD2, hydrolyzes phosphatidylcholine to generate phosphatidic acid (PA) and free choline ${ }^{62,69}$ (Fig. 3). PA is a bioactive lipid mediating signalling processes as well as membrane budding and fusion along the secretory, endolysosomal and autophagy pathway 69,70 . PLD1 overexpression was shown to promote the cell surface delivery of APP and neurite outgrowth in primary hippocampal neurons expressing FAD mutant versions of PS1, two processes that are defective in mutant neurons. Additionally, PLD1 negatively 
regulates the processing of APP by PS1, likely through modulation of PS1 activity (Fig. 2b) $62,71,72$. PLD1 also promotes the cell surface delivery of PS1 and physically interacts with this protein ${ }^{71,73}$. Future studies are needed to establish whether PLD1 modulates AD pathogenesis through the abovementioned mechanisms in vivo and whether it involves crosstalk with the metabolism of $\operatorname{PtdIns}(4,5) \mathrm{P}_{2}$, since its synthesis is stimulated by PA ${ }^{69}$.

In summary, studies on phospholipids, such as phosphoinositides and PA, have implicated these lipids in several processes controlling A $\beta$ generation, including the trafficking of APP and presenilin. This area thus has the potential to be explored for novel therapeutic interventions.

\section{Role of lipids in $A \beta$ misfolding and aggregation}

$A \beta$ is released in the lumen of organelles from the late secretory and endosomal systems as well as in the extracellular environment. $A \beta$ is believed to exert its toxic effects by interacting with cellular membranes and their associated proteins, which, in turn, modulate the folding of this peptide into higher-order structures of varying cytotoxic potential ${ }^{74,75}$. These $A \beta$ species have the ability to perturb the integrity and signaling properties of membranes they interact with. Thus, membrane-bound assembly- (or aggregate-) promoting factors, such as gangliosides, have received considerable attention.

Gangliosides are abundant membrane glycosphingolipids that are primary modulators of $A \beta$ aggregation ${ }^{74,75}$ (Suppl. Fig. 2). They are concentrated in the luminal leaflet of various cellular organelles and the outer leaflet of the plasma membrane, where they are found in raft-like lipid microdomains that also contain cholesterol. The main gangliosides in the brain are GM1, GD1a ( $a$-series) and GD1b and GT1b ( $b$-series) ${ }^{43}$. A link between gangliosides and $\mathrm{AD}$ was first suggested by studies showing aberrant expression levels and distribution of specific gangliosides in AD brain with significant regional differences ${ }^{76,77}$. Importantly, gangliosides, such as GM1, bind $A \beta$ and alter the conformation from random coils to more ordered structures with increased $\beta$-sheet content, which correlates with toxicity. Thus, cellsurface GM1 acts as a 'seed' for $A \beta$ aggregation in neurons as well as in nerve terminal preparations. This property increases with the aging process and is facilitated by cholesterolrich environments, indicating the process might occur in membrane rafts ${ }^{75,78}$. Interestingly, the presence of GM1-bound $A \beta(G A \beta)$ is associated with early pathological changes in $A D{ }^{79}$. FAD mutations within the $A \beta$ sequence alter the ganglioside-binding specificity, perhaps in part, accounting for differences in the phenotypic manifestations associated with the respective families.

Genetic evidence now strongly supports the hypothesis that gangliosides may be key disease-modifiers and modulators of $A \beta$ deposition. Ablation of GM2 synthase in a transgenic mouse model of AD leads to an accumulation of GM3 and a loss of GM1. This results in the accumulation of $A \beta$ in brain parenchyma, and more interestingly, in vascular smooth muscle tissue. This vascular deposition is reminiscent of the amyloid angiopathy occurring in patients carrying the Dutch APP mutation, which lies within the A $\beta$ sequence and enhances the affinity of $A \beta$ for GM $3{ }^{78}$. Perhaps more relevant for therapeutics, genetic ablation of GD3 synthase (GD3S) improves cognitive function and decreases the A $\beta$ plaque burden in a bigenic mouse expressing mutant versions of the APP (swAPP) and PSEN1 $(\triangle \mathrm{E} 9)$ genes ${ }^{80}$. Although $\mathrm{A} \beta$ fails to bind and exert neurotoxicity on GD3S null neurons and astrocytes, the precise nature of the protective mechanism conferred by GD3S ablation is unclear. In GD3S null cells, the decrease in $b$ - and $c$-series gangliosides is concomitant with an increase in $a$-series, such as GM1 and GM3 ${ }^{80}$ (Suppl. Fig. 1). Potential benefits derived from ganglioside-based therapies are highlighted by studies in a transgenic model of $\mathrm{AD}$, in which injections of GM1 were shown to decrease $\mathrm{A} \beta$ burden, likely by promoting 
degradation of $A \beta$ in the periphery ${ }^{81}$. Finally, gangliosides associated with $A \beta$ in neuritic plaques may mediate evasion from immune surveillance by interacting with a negative immune receptor expressed in microglia, Siglec-11. Thus, gangliosides may indirectly facilitate the formation and maintenance of amyloid plaques by decreasing clearance through microglial degradation ${ }^{82}$.

\section{Lipid mediators and modulators of $A \beta$ neurotoxicity and synaptic dysfunction}

$A \beta$ exerts its neurotoxicity primarily by interacting with cellular membranes leading to impairment of integrity and signaling properties. Synapses are particularly affected, not only because they are major sites of $A \beta$ release, but also because $A \beta$ release itself is enhanced by synaptic activity ${ }^{83,84}$. Furthermore, oligomeric assemblies of $A \beta$ appear to have high affinity for synaptic membranes, particularly dendritic spines ${ }^{85}$. Because synaptic dysfunction is likely to be the primary cause of cognitive impairment in the early stage of $\mathrm{AD}^{1,86}$, it is of paramount importance to fully understand the synaptotoxic signaling pathway dictated by $\mathrm{A} \beta$ and, in particular, the role of lipid changes in mediating this pathway. Central to the action of $A \beta$ on lipid metabolism appears to be the ability of this peptide to perturb calcium homeostasis ${ }^{87}$ and the subsequent dysregulation of calciumsensitive phospholipid-metabolizing enzymes (Fig. 3).

\section{Inositol lipids, phospholipase $\mathbf{C}$ and synaptojanin}

Early studies of AD brains showed a reduction in the levels of PtdIns ${ }^{61}$ and an increase in PLC activity as a result of $A \beta$ application on membrane fractions ${ }^{88}$ or due to expression of FAD mutants of presenilin ${ }^{66,89}$. Insights into the underlying mechanism have been provided by our recent study indicating that $\mathrm{A} \beta$ itself disrupts the metabolism of $\operatorname{PtdIns}(4,5) \mathrm{P}_{2}$ and that this phenomenon is required for its synaptotoxic action (Fig. 3) ${ }^{90}$. Indeed, $\operatorname{PtdIns}(4,5) \mathrm{P}_{2}$ levels decreased upon acute and chronic exposures to oligomeric $\mathrm{A} \beta 42$ at nanomolar concentrations. This effect required extracellular $\mathrm{Ca}^{2+}$ as well as PLC activity and partially depended on NMDA receptor function (Fig. 3). Blocking PtdIns $(4,5) \mathrm{P}_{2}$ breakdown by genetically reducing the level of a phosphoinositide phosphatase, synaptojanin 1, prevented A $\beta 42$ oligomers from suppressing long-term potentiation (LTP) in hippocampal slices (Fig. 3) ${ }^{90}$. Because synaptojanin 1 regulates clathrin-mediated synaptic vesicle recycling and the internalization of AMPA receptors ${ }^{65,91,92}$, haploinsufficiency of Synj 1 may counteract the ability of A $\beta 42$ oligomers to perturb the synaptic vesicle cycle presynaptically or promote the internalization of AMPA receptors (and perhaps also NMDA receptors) at the postsynapse, both of which are central to $A \beta$-mediated depression of synaptic transmission ${ }^{93,94}$. In contrast, the overexpression of Synj 1 due to triplication of chromosome 21, where it is located, and the resulting deficiency of $\operatorname{PtdIns}(4,5) \mathrm{P}_{2}$, correlate with learning deficits in transgenic mouse models of trisomy 21 (or Down syndrome) ${ }^{95}$. Because middle-aged individuals with Down syndrome develop AD pathology, including senile plaques, these studies suggest the intriguing possibility that trisomy 21-linked Synj 1 overexpression may confer a sensitized background for the synaptotoxic effects of $\mathrm{A} \beta$. The combined actions of Synj1 and A $\beta$ may inflict a dual "hit" upon PtdIns $(4,5) \mathrm{P}_{2}$ in the brains of individuals with Down syndrome.

While conversion of PtdIns $(4,5) \mathrm{P}_{2}$ to PtdIns $(3,4,5) \mathrm{P}_{3}$ by class I PI3Ks is key to cell survival, recent evidence suggests that it may paradoxically mediate synapse- and memory-impairing actions of $\mathrm{A} \beta$ in a fly model of $\mathrm{AD}{ }^{96}$. Indeed, expression of a secretory form of $\mathrm{A} \beta 42$ in the fly brain was shown to decrease long-term depression and to induce an age-dependent increase in oligomeric and fibrillar A $\beta 42$, which parallels memory loss and 
neurodegeneration. Whether these defects in PI3K signaling occur in mammalian neurons and more generally in $\mathrm{AD}$ brain remains to be discovered.

\section{Arachidonic acid and phospholipase A2}

Release of arachidonic acid (AA) from phospholipids through the PLA2 pathway (Fig. 3; Suppl. Fig. 3) produces a large family of metabolites, including prostaglandins and leukotrienes ${ }^{97}$. PLA2 products and their metabolites have been implicated in several ADrelevant aspects, including inflammation, glutamatergic transmission, synaptic plasticity and oxidative stress. Important clues implicating dysregulation of the PLA2 pathway in AD stemmed from post mortem studies showing an increase in the immunoreactivity of cytosolic PLA2 (cPLA2) ${ }^{98}$ and a reduction in the levels of phospholipid-bound AA in AD brain ${ }^{99}$. Other studies have identified cPLA2 as a key mediator of A $\beta$ oligomer-induced neuronal cell death acting in a cascade involving ROS formation and leading to downstream activation of a sphingomyelinase-ceramide pathway triggering apoptosis ${ }^{100,101}$. Recently, Mucke and colleagues utilized an unbiased approach to profile essential fatty acid metabolism in various brain regions from a transgenic model of $\mathrm{AD}$ ('J20'), which is associated with a significant age-dependent accumulation of $A \beta{ }^{102,103}$. An increase in AA as well as in various metabolites of this fatty acid was found selectively in the hippocampus. This led to the identification of a specific isoform of PLA2, group IVA (GIVA), which is $\mathrm{Ca}^{2+}$-dependent, highly expressed in the brain and hyperactivated in $\mathrm{AD}{ }^{102,103}$. Importantly, genetic ablation of GIVA-PLA2 improved cognition, viability and behavior, in the context of the J20 APP transgenic model, despite the elevated A $\beta$ burden ${ }^{102}$. A partial mechanistic understanding of $A \beta$-mediated neurotoxicity was provided by data showing that GIVA-PLA2 activation by $A \beta$ and direct applications of the product AA both stimulate AMPA-mediated excitotoxicity in acutely-treated primary neuronal cultures by elevating the cell surface levels of AMPA receptor ${ }^{102,103}$. Thus, GIVA-PLA2 is likely to be one of the key $\mathrm{Ca}^{2+}$ effectors mediating the acute and chronic synaptotoxic actions of $A \beta$.

\section{Phosphatidic acid and phospholipase D}

Several early post mortem studies reported changes in PLD activity in AD brain ${ }^{62}$, a link that was corroborated by studies in cell culture models showing that APP overexpression and extracellular $A \beta$ applications enhance PLD activity ${ }^{62}$. Recently, our lab has provided robust in vitro and in vivo evidence for a role for the PLD2 isoform in mediating the synaptotoxic actions of $A \beta{ }^{104}$. Indeed, we found that $A \beta 42$ oligomers enhance total PLD activity in primary cortical neurons and that this increase is abolished in mouse neurons lacking PLD2. Evidence indicating that PLD2 is required for the synaptotoxic action of $\mathrm{A} \beta 42$ was provided by data showing that genetic ablation of this enzyme confers protection against the suppressive effects of A $\beta 42$ on LTP and memory impairment in a mouse model of AD expressing mutant APP (i.e., Swedish APP or SwAPP) (Fig. 3) ${ }^{104}$ \}. Using mass spectrometry, this study also identified a molecular species of PA that is controlled by PLD2, selectively upregulated in response to SwAPP overexpression and has been previously linked to neurodegeneration ${ }^{104,105}$. Thus, specific pools of PA and PLD2 are likely to play a key role in $\mathrm{AD}$ pathogenesis, although the molecular basis for this phenomenon is unknown.

\section{Regulation of cholesterol homeostasis and sphingolipid metabolism by $A \beta$}

$A \beta$ is known to regulate the metabolism of cholesterol and sphingolipids, both of which also affect APP processing ${ }^{47,106}$. Indeed, A $\beta 40$ suppresses the mevalonate pathway by inhibiting HMG-coA reductase, thus decreasing the levels of cholesterol ${ }^{106}$. Additionally, while micromolar concentrations of $\mathrm{A} \beta 42$ induce oxidative stress and neurotoxicity by enhancing ceramide production through activation of neutral sphingomyelinase (N-SMase) ${ }^{101}$, physiologically-relevant concentrations of $\mathrm{A} \beta 42$ (i.e., low $\mathrm{pM}$ to $\mathrm{nM}$ range) stimulate $\mathrm{SM}$ 
hydrolysis and ceramide production via the same enzyme without affecting cell viability 47,106 . In light of a growing number of studies pointing to the role of low, physiological (picomolar) A $\beta$ concentrations in synaptic function (see for instance ref. ${ }^{107}$ ), the latter study suggests that regulation of lipid metabolism by APP and its metabolites may be relevant to neuronal physiology, although the signaling pathways involved are poorly understood.

\section{Linking lipid metabolism to tau pathology}

In contrast to APP and the secretases (which are membrane-bound), tau is a cytoplasmic protein that interacts with and stabilizes microtubules and although several types of membranous organelles critically depend on microtubules for their subcellular localization and intracellular transport, the relationship of tau with lipids is not direct. However, tau (and tau pathology) can be modulated by lipids in several ways. First, the A $\beta$ signaling pathway, as highlighted above, perturbs biochemical pathways involving lipid metabolizing enzymes and bioactive lipids, ultimately affecting tau phosphorylation ${ }^{108}$. Second, cholesterol levels are a key parameter controlling $\mathrm{A} \beta$-induced tau proteolysis by calpain ${ }^{109}$ and proteolytic cleavage of tau by this protease, but also by caspases, appears to be an early step leading to tau pathology 110,111 . A pool of hyperphosphorylated tau is also present in lipid rafts, along with APP metabolites (including dimeric A $\beta$ ), BACE1, the $\gamma$-secretase complex and ApoE, suggesting that significant crosstalk may exist between $A \beta$ and tau at the raft interface ${ }^{112}$. Furthermore, there is evidence that kinases implicated in tau phosphorylation, such as Cdk5 and GSK-3 $\beta$, are activated on cellular membranes and thus dysregulation of lipid metabolism may affect the activity of these kinases ${ }^{113,114}$. Cdk5, in turn, phosphorylates the lipid kinase Vps34 ${ }^{115}$, whose product PtdIns3P, may regulate the clearance of tau aggregates by stimulating the autophagy pathway ${ }^{116}$. Finally, a growing scientific community is investigating the mechanisms through which tau aggregates may be secreted or exert their prion-like infectious properties across cell membranes, thus propagating the tau pathology 117 .

Although the link between lipid dysregulation and tau pathology is not well understood in $\mathrm{AD}$, the occurrence of neurofibrillary tangles in the brain of individuals with lipid storage disorders, such as Niemann-Pick type C (NPC) disease, suggests a tight relationship between lipid trafficking defects and tau pathology ${ }^{118}$. NPC is an inherited autosomal recessive neurodegenerative disorder that causes childhood or early adulthood death and stems from mutation in either of two functionally related genes, NPC1 and NPC2, which encode late endosome/lysosome-enriched proteins proposed to be involved in the trafficking of cholesterol ${ }^{119}$. Loss of function mutant versions of NPC1 or NPC2 results in higher endosomal levels of unesterified cholesterol and SM in peripheral tissues as well as of multiple glycosphingolipids in the central nervous system, likely reflecting the inability of these lipids to efficiently exit this compartment and traffic to their normal destinations in cells ${ }^{119}$. Although NPC is not associated with increased A $\beta$ plaque burden, the lipid trafficking defect in NPC has been linked to enhanced amyloidogenic processing of APP in endosomes. As in AD, the relationship between tau pathology and aberrant APP metabolism is unclear, although the emerging notion of a central role for lipid trafficking defects and endosomal dysfunction in NPC suggests the existence of shared pathogenic mechanisms between this disorder and $\mathrm{AD}$.

\section{Lipid-focused therapeutic approaches}

Despite a myriad of studies connecting lipid metabolism to AD pathogenesis, relatively few therapeutic approaches have exploited this connection thus far, with the exception of drugs affecting cholesterol metabolism, such as statins and ACAT inhibitors. Indeed, current drug 
development strategies mainly rely on the repositioning of existing therapeutic agents that have been originally developed for other disease indications, such as atherosclerosis. While the progress in the latter area is summarized here, this section will also elaborate on promising new leads stemming from research on phospholipids as well as lipid-based nutritional supplements.

\section{Statins and ACAT inhibitors}

As mentioned above, statins inhibit the enzyme HMG-CoA reductase which catalyzes the rate-limiting step in cholesterol biosynthesis (Suppl. Fig. 1). Retrospective case control studies suggest that statins reduce the risk of developing $\mathrm{AD}^{120,121}$, but clinical trials and prospective cohort studies have produced inconsistent, mixed results ${ }^{122,123}$. One of the more encouraging studies showed that statins prevent brain-trauma-induced $A \beta$ elevation in mice, raising the possibility that an activity/injury-dependent, statin-sensitive pool of $A \beta$ may be present in the brain ${ }^{124}$. This is relevant because brain trauma may be a significant cause of SAD. Overall, despite early promise maintaining statins may influence AD via inhibitory effects on amyloidogenesis, anti-inflammatory actions or modification of cardiovascular risk factors 106,125 , results from clinical studies have been rather disappointing.

A more recent therapeutic approach involves small molecule inhibitors of ACAT1, an enzyme that mediates the esterification of cholesterol, as discussed above (Suppl. Fig. 1). CP-113,818 and CI-1011 have demonstrated efficacy in preclinical models of AD 16,17. However, important challenges associated with the development of ACAT inhibitors for AD indication are safety concerns and their ability to cross the blood-brain barrier. Additionally, more research is needed to better understand the molecular mechanisms underlying the amelioration of $\mathrm{AD}$ phenotypes by these compounds.

\section{Emerging lipid-centric therapeutic approaches}

Genetic, pharmacological and cell biological studies continue to explore the possibility of targeting effectors and pathways of lipid metabolism relevant to AD. While many molecular targets, including cPLA2, Synj1, PLD2 and nSMase, are being validated at the genetic level, further studies are needed to assess the "drugability" of these targets and identify chemical probes that are suitable for further therapeutic development. Positive modulation of the postsynaptic ApoE receptor 2 by reelin also represents a promising avenue, as reelin inhibits the synaptotoxic action of $\mathrm{A} \beta$ by promoting glutamatergic transmission in depressed synapses 126 .

While major research efforts are in progress to identify cellular effectors and enzymes of lipid metabolism, lipids themselves have been considered for therapeutic use as well as preventive agents for $\mathrm{AD}$. Epidemiological studies suggest that reduced intake of omega-3 fatty acids elevates the risk of $\mathrm{AD}^{127}$. Docosahexaenoic acid (DHA), the most popular omega-3 fatty acid used as a nutritional supplement, has been shown to exert multiple cellular effects antagonizing AD-associated phenotypes, including reduced $A \beta$ and neuroprotection against $A \beta$-induced synaptotoxicity ${ }^{127}$. While the exact cellular mechanisms underlying these actions are unclear, competition with an endogenous substrate, such as arachidonic acid (AA), may give rise to profound downstream changes in AA and AA-associated signaling pathways which have also been implicated in $\mathrm{AD}^{102}$. Alternatively, DHA metabolites, such as the docosanoid neuroprotectin D1, may mediate some of the protective effects by counteracting pro-apoptotic as well as neuro-inflammatory signaling associated with $\mathrm{AD}^{128}$. Recent work showed that DHA can also reduce $\mathrm{A} \beta$ levels by inhibiting both $\beta$-and $\gamma$-secretase activities while potentiating $\alpha$-secretase cleavage, thus offering a novel perspective on how this lipid may exert neuroprotection ${ }^{129}$. While 
polyunsaturated fatty acids, such as DHA, are generally viewed as neuroprotective, they are also primary substrates for lipid peroxidation, a phenomenon that is prominent in AD and other neurodegenerative disorders (Box 3). Thus, there long-term use should be considered with caution. Finally, recent genome-wide association studies (GWAS) have identified new risk genes in $\mathrm{AD}^{130}$, some of which encode proteins that are linked to lipid metabolism (e.g., clusterin/Apolipoprotein J, cholesteryl ester transfer protein) ${ }^{131-133}$. Despite the plausibility of the biological and pathological relevance of these gene products in AD, further validation studies are needed to better understand their role in AD pathogenesis.

\section{Conclusion and perspectives}

One of the most outstanding questions in the field of $\mathrm{AD}$ and lipid research is the identification of the precise lipid-based molecular mechanisms governing AD-relevant processes that are intimately linked to the physicochemical and signaling properties of membranes. Specifically, what lipids modulate the targeting, trafficking, specificity and activity of the relevant secretases? Do specific lipid signatures predispose for or protect against AD? Are there common denominators in the lipid profiles of FAD and SAD-affected individuals that may help to explain or provide new perspectives on the convergence of these etiologically-distinct disorders toward AD pathological features? What lipid changes are causal for AD-linked pathogenicity and what changes are simple epiphenomena? Finally, which lipids and lipid metabolizing enzymes can be targeted or exploited for therapeutics?

None of these outstanding questions could be adequately addressed without the technological advance in lipid analysis, namely, the use of 'lipidomics' 134,135. This systems-level analysis allows for the identification of a wide variety of lipid changes occurring as a result of experimental manipulations or a diseased state, with the anticipation that these lipid changes may instruct us on the biochemical pathways that are affected or causal in the disease. Similar to genome-wide and proteomics-based approaches, lipidomics can unmask crosstalk between biochemical pathways and provide essential mechanistic insights into the molecular basis of cellular or organismal changes. Additionally, lipidomics offers enormous potential for the identification of disease-linked body-fluid biomarkers, which can prove particularly helpful as diagnostic tools at early stages of dementia and in the diagnosis of $\mathrm{AD}$-specific mild cognitive impairment. This rapidly growing area has already begun to address lipid changes in $\mathrm{AD}$ brains $108,136,137$, in animal models of $\mathrm{AD}{ }^{102,136,138,139}$ and in $\mathrm{A} \beta$-treated cells ${ }^{108}$. The prediction is that the number of such studies will grow exponentially in the near future and touch upon multiple facets of AD and other neurodegenerative disorders.

\section{Supplementary Material}

Refer to Web version on PubMed Central for supplementary material.

\section{Acknowledgments}

We would like to thank Robin Chan, Tiago Gil Oliveira, Diego Berman and Laura Beth McIntire for critical reading of the manuscript. Work from the authors is supported by US National Institutes of Health grants NS056049, HD05547 and AG033212 (G.D.P.) and NS074536 and AG033199 (T.-W.K.), American Health Assistance Foundation (T.-W.K.), Cure Alzheimer's Fund (T.-W.K.), Alzheimer's Drug Discovery Foundation (T.W.K.), the Alzheimer's Association (G.D.P.) and the McKnight Foundation (G.D.P.). 


\section{Bibliography}

1. Haass C, Selkoe DJ. Soluble protein oligomers in neurodegeneration: lessons from the Alzheimer's amyloid beta-peptide. Nat Rev Mol Cell Biol. 2007; 8:101-112. [PubMed: 17245412]

2. Tanzi RE, Bertram L. Twenty years of the Alzheimer's disease amyloid hypothesis: a genetic perspective. Cell. 2005; 120:545-555. [PubMed: 15734686]

3. Ballatore C, Lee VM, Trojanowski JQ. Tau-mediated neurodegeneration in Alzheimer's disease and related disorders. Nat Rev Neurosci. 2007; 8:663-672. [PubMed: 17684513]

4. Small SA, Duff K. Linking Abeta and tau in late-onset Alzheimer's disease: a dual pathway hypothesis. Neuron. 2008; 60:534-542. [PubMed: 19038212]

5. Foley P. Lipids in Alzheimer's disease: A century-old story. Biochimica et biophysica acta. 2010; 1801:750-753. [PubMed: 20471492]

6. Corder EH, et al. Gene dose of apolipoprotein E type 4 allele and the risk of Alzheimer's disease in late onset families. Science. 1993; 261:921-923. [PubMed: 8346443]

7. Bertram L, Tanzi RE. Thirty years of Alzheimer's disease genetics: the implications of systematic meta-analyses. Nat Rev Neurosci. 2008; 9:768-778. [PubMed: 18802446]

8. Bu G. Apolipoprotein E and its receptors in Alzheimer's disease: pathways, pathogenesis and therapy. Nat Rev Neurosci. 2009; 10:333-344. [PubMed: 19339974]

9. Kim J, Basak JM, Holtzman DM. The role of apolipoprotein E in Alzheimer's disease. Neuron. 2009; 63:287-303. [PubMed: 19679070]

10. Hartmann T, Kuchenbecker J, Grimm MO. Alzheimer's disease: the lipid connection. J Neurochem. 2007; 103(Suppl 1):159-170. [PubMed: 17986151]

11. Dietschy JM, Turley SD. Cholesterol metabolism in the brain. Curr Opin Lipidol. 2001; 12:105112. [PubMed: 11264981]

12. Mesmin B, Maxfield FR. Intracellular sterol dynamics. Biochim Biophys Acta. 2009; 1791:636645. [PubMed: 19286471]

13. Vance JE, Hayashi H, Karten B. Cholesterol homeostasis in neurons and glial cells. Semin Cell Dev Biol. 2005; 16:193-212. [PubMed: 15797830]

14. Chang TY, Chang CC, Ohgami N, Yamauchi Y. Cholesterol sensing, trafficking, and esterification. Annu Rev Cell Dev Biol. 2006; 22:129-157. [PubMed: 16753029]

15. Puglielli L, et al. Acyl-coenzyme A: cholesterol acyltransferase modulates the generation of the amyloid beta-peptide. Nat Cell Biol. 2001; 3:905-912. [PubMed: 11584272]

16. Bhattacharyya R, Kovacs DM. ACAT inhibition and amyloid beta reduction. Biochim Biophys Acta. 2010

17. Hutter-Paier B, et al. The ACAT inhibitor CP-113,818 markedly reduces amyloid pathology in a mouse model of Alzheimer's disease. Neuron. 2004; 44:227-238. [PubMed: 15473963]

18. Bryleva EY, et al. ACAT1 gene ablation increases 24(S)-hydroxycholesterol content in the brain and ameliorates amyloid pathology in mice with AD. Proc Natl Acad Sci U S A. 2010; 107:30813086. [PubMed: 20133765]

19. Hirsch-Reinshagen V, Burgess BL, Wellington CL. Why lipids are important for Alzheimer disease? Mol Cell Biochem. 2009; 326:121-129. [PubMed: 19116777]

20. Tall AR. Cholesterol efflux pathways and other potential mechanisms involved in the atheroprotective effect of high density lipoproteins. J Intern Med. 2008; 263:256-273. [PubMed: 18271871]

21. Sun Y, Yao J, Kim TW, Tall AR. Expression of liver X receptor target genes decreases cellular amyloid beta peptide secretion. J Biol Chem. 2003; 278:27688-27694. [PubMed: 12754201]

22. Hirsch-Reinshagen V, et al. The absence of ABCA1 decreases soluble ApoE levels but does not diminish amyloid deposition in two murine models of Alzheimer disease. The Journal of biological chemistry. 2005; 280:43243-43256. [PubMed: 16207707]

23. Koldamova R, Staufenbiel M, Lefterov I. Lack of ABCA1 considerably decreases brain ApoE level and increases amyloid deposition in APP23 mice. J Biol Chem. 2005; 280:43224-43235. [PubMed: 16207713] 
24. Wahrle SE, et al. Deletion of Abca1 increases Abeta deposition in the PDAPP transgenic mouse model of Alzheimer disease. J Biol Chem. 2005; 280:43236-43242. [PubMed: 16207708]

25. Simons M, et al. Cholesterol depletion inhibits the generation of beta-amyloid in hippocampal neurons. Proc Natl Acad Sci U S A. 1998; 95:6460-6464. [PubMed: 9600988]

26. Vetrivel KS, Thinakaran G. Membrane rafts in Alzheimer's disease beta-amyloid production. Biochim Biophys Acta. 2010

27. Kalvodova L, et al. Lipids as modulators of proteolytic activity of BACE: involvement of cholesterol, glycosphingolipids, and anionic phospholipids in vitro. J Biol Chem. 2005; 280:36815-36823. [PubMed: 16115865]

28. Fassbender K, et al. Simvastatin strongly reduces levels of Alzheimer's disease beta - amyloid peptides Abeta 42 and Abeta 40 in vitro and in vivo. Proc Natl Acad Sci U S A. 2001; 98:58565861. [PubMed: 11296263]

29. Wahrle S, et al. Cholesterol-dependent gamma-secretase activity in buoyant cholesterol-rich membrane microdomains. Neurobiol Dis. 2002; 9:11-23. [PubMed: 11848681]

30. Osenkowski P, Ye W, Wang R, Wolfe MS, Selkoe DJ. Direct and potent regulation of gammasecretase by its lipid microenvironment. J Biol Chem. 2008; 283:22529-22540. [PubMed: 18539594]

31. Osawa $S$, et al. Phosphoinositides suppress gamma-secretase in both the detergent-soluble and insoluble states. J Biol Chem. 2008; 283:19283-19292. [PubMed: 18480063]

32. Riddell DR, Christie G, Hussain I, Dingwall C. Compartmentalization of beta-secretase (Asp2) into low-buoyant density, noncaveolar lipid rafts. Curr Biol. 2001; 11:1288-1293. [PubMed: 11525745]

33. Ehehalt R, Keller P, Haass C, Thiele C, Simons K. Amyloidogenic processing of the Alzheimer beta-amyloid precursor protein depends on lipid rafts. J Cell Biol. 2003; 160:113-123. [PubMed: 12515826]

34. Vetrivel KS, et al. Alzheimer disease Abeta production in the absence of S-palmitoylationdependent targeting of BACE1 to lipid rafts. J Biol Chem. 2009; 284:3793-3803. [PubMed: 19074428]

35. Benjannet $\mathrm{S}$, et al. Post-translational processing of beta-secretase (beta-amyloid-converting enzyme) and its ectodomain shedding. The pro- and transmembrane/cytosolic domains affect its cellular activity and amyloid-beta production. J Biol Chem. 2001; 276:10879-10887. [PubMed: 11152688]

36. Hattori C, et al. BACE1 interacts with lipid raft proteins. J Neurosci Res. 2006; 84:912-917. [PubMed: 16823808]

37. Marquer C, et al. Local cholesterol increase triggers amyloid precursor protein-Bace1 clustering in lipid rafts and rapid endocytosis. The FASEB journal: official publication of the Federation of American Societies for Experimental Biology. 2011

38. Yoon IS, et al. Low-density lipoprotein receptor-related protein promotes amyloid precursor protein trafficking to lipid rafts in the endocytic pathway. FASEB J. 2007; 21:2742-2752. [PubMed: 17463224]

39. Schneider A, et al. Flotillin-dependent clustering of the amyloid precursor protein regulates its endocytosis and amyloidogenic processing in neurons. J Neurosci. 2008; 28:2874-2882. [PubMed: 18337418]

40. Urano Y, et al. Association of active gamma-secretase complex with lipid rafts. J Lipid Res. 2005; 46:904-912. [PubMed: 15716592]

41. Vetrivel KS, et al. Spatial segregation of gamma-secretase and substrates in distinct membrane domains. J Biol Chem. 2005; 280:25892-25900. [PubMed: 15886206]

42. Hannun YA, Obeid LM. Principles of bioactive lipid signalling: lessons from sphingolipids. Nat Rev Mol Cell Biol. 2008; 9:139-150. [PubMed: 18216770]

43. Posse de Chaves E, Sipione S. Sphingolipids and gangliosides of the nervous system in membrane function and dysfunction. FEBS Lett. 2010; 584:1748-1759. [PubMed: 20006608]

44. He X, Huang Y, Li B, Gong CX, Schuchman EH. Deregulation of sphingolipid metabolism in Alzheimer's disease. Neurobiol Aging. 2008; 31:398-408. [PubMed: 18547682] 
45. Puglielli L, Ellis BC, Saunders AJ, Kovacs DM. Ceramide stabilizes beta-site amyloid precursor protein-cleaving enzyme 1 and promotes amyloid beta-peptide biogenesis. The Journal of biological chemistry. 2003; 278:19777-19783. [PubMed: 12649271]

46. Castro BM, Silva LC, Fedorov A, de Almeida RF, Prieto M. Cholesterol-rich fluid membranes solubilize ceramide domains: implications for the structure and dynamics of mammalian intracellular and plasma membranes. J Biol Chem. 2009; 284:22978-22987. [PubMed: 19520848]

47. Grimm MO, et al. Regulation of cholesterol and sphingomyelin metabolism by amyloid-beta and presenilin. Nat Cell Biol. 2005; 7:1118-1123. [PubMed: 16227967]

48. Sawamura N, et al. Modulation of amyloid precursor protein cleavage by cellular sphingolipids. J Biol Chem. 2004; 279:11984-11991. [PubMed: 14715666]

49. Fantini J, Garmy N, Mahfoud R, Yahi N. Lipid rafts: structure, function and role in HIV, Alzheimer's and prion diseases. Expert Rev Mol Med. 2002; 4:1-22. [PubMed: 14987385]

50. Zhang D, Manna M, Wohland T, Kraut R. Alternate raft pathways cooperate to mediate slow diffusion and efficient uptake of a sphingolipid tracer to degradative and recycling compartments. J Cell Sci. 2009; 122:3715-3728. [PubMed: 19773361]

51. Hooff GP, Wood WG, Muller WE, Eckert GP. Isoprenoids, small GTPases and Alzheimer's disease. Biochim Biophys Acta. 2010

52. Liao JK, Laufs U. Pleiotropic effects of statins. Annu Rev Pharmacol Toxicol. 2005; 45:89-118. [PubMed: 15822172]

53. Cole SL, Vassar R. Isoprenoids and Alzheimer's disease: a complex relationship. Neurobiol Dis. 2006; 22:209-222. [PubMed: 16406223]

54. Edlund C, Soderberg M, Kristensson K, Dallner G. Ubiquinone, dolichol, and cholesterol metabolism in aging and Alzheimer's disease. Biochem Cell Biol. 1992; 70:422-428. [PubMed: 1449707]

55. Eckert GP, et al. Regulation of the brain isoprenoids farnesyl- and geranylgeranylpyrophosphate is altered in male Alzheimer patients. Neurobiol Dis. 2009; 35:251-257. [PubMed: 19464372]

56. Zhou Y, et al. Nonsteroidal anti-inflammatory drugs can lower amyloidogenic Abeta42 by inhibiting Rho. Science. 2003; 302:1215-1217. [PubMed: 14615541]

57. Weggen S, Rogers M, Eriksen J. NSAIDs: small molecules for prevention of Alzheimer's disease or precursors for future drug development? Trends in pharmacological sciences. 2007; 28:536543. [PubMed: 17900710]

58. Kukar T, et al. Diverse compounds mimic Alzheimer disease-causing mutations by augmenting Abeta42 production. Nat Med. 2005; 11:545-550. [PubMed: 15834426]

59. Pedrini S, et al. Modulation of statin-activated shedding of Alzheimer APP ectodomain by ROCK. Plos Medicine. 2005; 2:69-78.

60. Cole SL, et al. Statins cause intracellular accumulation of amyloid precursor protein, betasecretase-cleaved fragments, and amyloid beta-peptide via an isoprenoid-dependent mechanism. J Biol Chem. 2005; 280:18755-18770. [PubMed: 15718241]

61. Stokes CE, Hawthorne JN. Reduced phosphoinositide concentrations in anterior temporal cortex of Alzheimer-diseased brains. J Neurochem. 1987; 48:1018-1021. [PubMed: 3029323]

62. Oliveira TG, Di Paolo G. Phospholipase D in brain function and Alzheimer's disease. Biochim Biophys Acta. 2010; 1801:799-905. [PubMed: 20399893]

63. Petanceska SS, Gandy S. The phosphatidylinositol 3-kinase inhibitor wortmannin alters the metabolism of the Alzheimer's amyloid precursor protein. Journal of Neurochemistry. 1999; 73:2316-2320. [PubMed: 10582589]

64. Haugabook SJ, et al. Reduction of Abeta accumulation in the Tg2576 animal model of Alzheimer's disease after oral administration of the phosphatidyl-inositol kinase inhibitor wortmannin. FASEB J. 2001; 15:16-18. [PubMed: 11099491]

65. Di Paolo G, De Camilli P. Phosphoinositides in cell regulation and membrane dynamics. Nature. 2006; 443:651-657. [PubMed: 17035995]

66. Landman N, et al. Presenilin mutations linked to familial Alzheimer's disease cause an imbalance in phosphatidylinositol 4,5-bisphosphate metabolism. Proc Natl Acad Sci U S A. 2006; 103:19524-19529. [PubMed: 17158800] 
67. Yoo AS, et al. Presenilin-mediated modulation of capacitative calcium entry. Neuron. 2000; 27:561-572. [PubMed: 11055438]

68. Rossner S. New players in old amyloid precursor protein-processing pathways. Int J Dev Neurosci. 2004; 22:467-474. [PubMed: 15465276]

69. Jenkins GM, Frohman MA. Phospholipase D: a lipid centric review. Cell Mol Life Sci. 2005; 62:2305-2316. [PubMed: 16143829]

70. Dall'armi C, et al. The phospholipase D1 pathway modulates macroautophagy. Nat Commun. 2010; 1:142. [PubMed: 21266992]

71. Cai D, et al. Presenilin-1 uses phospholipase D1 as a negative regulator of beta-amyloid formation. Proc Natl Acad Sci U S A. 2006; 103:1941-1946. [PubMed: 16449386]

72. Cai D, et al. Phospholipase D1 corrects impaired betaAPP trafficking and neurite outgrowth in familial Alzheimer's disease-linked presenilin-1 mutant neurons. Proc Natl Acad Sci U S A. 2006; 103:1936-1940. [PubMed: 16449385]

73. Liu Y, et al. Intracellular trafficking of presenilin 1 is regulated by beta-amyloid precursor protein and phospholipase D1. J Biol Chem. 2009

74. Ariga T, McDonald MP, Yu RK. Role of ganglioside metabolism in the pathogenesis of Alzheimer's disease--a review. J Lipid Res. 2008; 49:1157-1175. [PubMed: 18334715]

75. Matsuzaki K, Kato K, Yanagisawa K. Abeta polymerization through interaction with membrane gangliosides. Biochim Biophys Acta. 2010

76. Kracun I, Kalanj S, Cosovic C, Talan-Hranilovic J. Brain gangliosides in Alzheimer's disease. J Hirnforsch. 1990; 31:789-793. [PubMed: 2092064]

77. Kracun I, et al. Human brain gangliosides in development, aging and disease. Int J Dev Biol. 1991; 35:289-295. [PubMed: 1814411]

78. Yanagisawa K. Role of gangliosides in Alzheimer's disease. Biochim Biophys Acta. 2007; 1768:1943-1951. [PubMed: 17321494]

79. Yanagisawa K, McLaurin J, Michikawa M, Chakrabartty A, Ihara Y. Amyloid beta-protein (A beta) associated with lipid molecules: immunoreactivity distinct from that of soluble A beta. FEBS Lett. 1997; 420:43-46. [PubMed: 9450547]

80. Bernardo A, et al. Elimination of GD3 synthase improves memory and reduces amyloid-beta plaque load in transgenic mice. Neurobiol Aging. 2009; 30:1777-1791. [PubMed: 18258340]

81. Matsuoka Y, et al. Novel therapeutic approach for the treatment of Alzheimer's disease by peripheral administration of agents with an affinity to beta-amyloid. J Neurosci. 2003; 23:29-33. [PubMed: 12514198]

82. Salminen A, Kaarniranta K. Siglec receptors and hiding plaques in Alzheimer's disease. J Mol Med. 2009; 87:697-701. [PubMed: 19390836]

83. Kamenetz F, et al. APP processing and synaptic function. Neuron. 2003; 37:925-937. [PubMed: 12670422]

84. Cirrito JR, et al. Synaptic activity regulates interstitial fluid amyloid-beta levels in vivo. Neuron. 2005; 48:913-922. [PubMed: 16364896]

85. Lacor PN, et al. Abeta oligomer-induced aberrations in synapse composition, shape, and density provide a molecular basis for loss of connectivity in Alzheimer's disease. J Neurosci. 2007; 27:796-807. [PubMed: 17251419]

86. Palop JJ, Mucke L. Amyloid-beta-induced neuronal dysfunction in Alzheimer's disease: from synapses toward neural networks. Nat Neurosci. 2010; 13:812-818. [PubMed: 20581818]

87. Green KN, LaFerla FM. Linking calcium to Abeta and Alzheimer's disease. Neuron. 2008; 59:190-194. [PubMed: 18667147]

88. Wallace MA. Effects of Alzheimer's disease-related beta amyloid protein fragments on enzymes metabolizing phosphoinositides in brain. Biochim Biophys Acta. 1994; 1227:183-187. [PubMed: 7986826]

89. Cedazo-Minguez A, Popescu BO, Ankarcrona M, Nishimura T, Cowburn RF. The presenilin 1 deltaE9 mutation gives enhanced basal phospholipase $\mathrm{C}$ activity and a resultant increase in intracellular calcium concentrations. J Biol Chem. 2002; 277:36646-36655. [PubMed: 12121968] 
90. Berman DE, et al. Oligomeric amyloid-beta peptide disrupts phosphatidylinositol-4,5-bisphosphate metabolism. Nat Neurosci. 2008; 11:547-554. [PubMed: 18391946]

91. Irie F, Okuno M, Pasquale EB, Yamaguchi Y. EphrinB-EphB signalling regulates clathrinmediated endocytosis through tyrosine phosphorylation of synaptojanin 1. Nat Cell Biol. 2005; 7:501-509. [PubMed: 15821731]

92. Gong LW, De Camilli P. Regulation of postsynaptic AMPA responses by synaptojanin 1. Proc Natl Acad Sci U S A. 2008; 105:17561-17566. [PubMed: 18987319]

93. Hsieh $\mathrm{H}$, et al. AMPAR removal underlies Abeta-induced synaptic depression and dendritic spine loss. Neuron. 2006; 52:831-843. [PubMed: 17145504]

94. Snyder EM, et al. Regulation of NMDA receptor trafficking by amyloid-beta. Nat Neurosci. 2005; 8:1051-1058. [PubMed: 16025111]

95. Voronov SV, et al. Synaptojanin 1-linked phosphoinositide dyshomeostasis and cognitive deficits in mouse models of Down's syndrome. Proc Natl Acad Sci U S A. 2008; 105:9415-9420. [PubMed: 18591654]

96. Chiang HC, Wang L, Xie Z, Yau A, Zhong Y. PI3 kinase signaling is involved in Abeta-induced memory loss in Drosophila. Proc Natl Acad Sci U S A. 2010; 107:7060-7065. [PubMed: 20351282]

97. van Meer G, Voelker DR, Feigenson GW. Membrane lipids: where they are and how they behave. Nat Rev Mol Cell Biol. 2008; 9:112-124. [PubMed: 18216768]

98. Stephenson DT, Lemere CA, Selkoe DJ, Clemens JA. Cytosolic phospholipase A2 (cPLA2) immunoreactivity is elevated in Alzheimer's disease brain. Neurobiol Dis. 1996; 3:51-63. [PubMed: 9173912]

99. Prasad MR, Lovell MA, Yatin M, Dhillon H, Markesbery WR. Regional membrane phospholipid alterations in Alzheimer's disease. Neurochem Res. 1998; 23:81-88. [PubMed: 9482271]

100. Kriem B, et al. Cytosolic phospholipase A2 mediates neuronal apoptosis induced by soluble oligomers of the amyloid-beta peptide. FASEB J. 2005; 19:85-87. [PubMed: 15486059]

101. Malaplate-Armand C, et al. Soluble oligomers of amyloid-beta peptide induce neuronal apoptosis by activating a cPLA2-dependent sphingomyelinase-ceramide pathway. Neurobiol Dis. 2006; 23:178-189. [PubMed: 16626961]

102. Sanchez-Mejia RO, et al. Phospholipase A2 reduction ameliorates cognitive deficits in a mouse model of Alzheimer's disease. Nat Neurosci. 2008; 11:1311-1318. [PubMed: 18931664]

103. Sanchez-Mejia RO, Mucke L. Phospholipase A2 and arachidonic acid in Alzheimer's disease. Biochim Biophys Acta. 2010; 1801:784-790. [PubMed: 20553961]

104. Oliveira TG, et al. Phospholipase d2 ablation ameliorates Alzheimer's disease-linked synaptic dysfunction and cognitive deficits. The Journal of neuroscience: the official journal of the Society for Neuroscience. 2010; 30:16419-16428. [PubMed: 21147981]

105. Raghu P, et al. Rhabdomere biogenesis in Drosophila photoreceptors is acutely sensitive to phosphatidic acid levels. Journal of Cell Biology. 2009; 185:129-145. [PubMed: 19349583]

106. Grosgen S, Grimm MO, Friess P, Hartmann T. Role of amyloid beta in lipid homeostasis. Biochim Biophys Acta. 2010

107. Puzzo D, et al. Picomolar amyloid-beta positively modulates synaptic plasticity and memory in hippocampus. J Neurosci. 2008; 28:14537-14545. [PubMed: 19118188]

108. Ryan SD, et al. Amyloid- $\{$ beta 42 signals tau hyperphosphorylation and compromises neuronal viability by disrupting alkylacylglycerophosphocholine metabolism. Proc. Natl Acad Sci U S A. 2009

109. Nicholson AM, Ferreira A. Increased membrane cholesterol might render mature hippocampal neurons more susceptible to beta-amyloid-induced calpain activation and tau toxicity. J Neurosci. 2009; 29:4640-4651. [PubMed: 19357288]

110. Johnson GV. Tau phosphorylation and proteolysis: insights and perspectives. J Alzheimers Dis. 2006; 9:243-250. [PubMed: 16914862]

111. de Calignon A, et al. Caspase activation precedes and leads to tangles. Nature. 2010; 464:12011204. [PubMed: 20357768] 
112. Kawarabayashi T, et al. Dimeric amyloid beta protein rapidly accumulates in lipid rafts followed by apolipoprotein $\mathrm{E}$ and phosphorylated tau accumulation in the $\mathrm{Tg} 2576$ mouse model of Alzheimer's disease. J Neurosci. 2004; 24:3801-3809. [PubMed: 15084661]

113. Hernandez P, Lee G, Sjoberg M, Maccioni RB. Tau phosphorylation by cdk5 and Fyn in response to amyloid peptide Abeta (25-35): involvement of lipid rafts. J Alzheimers Dis. 2009; 16:149156. [PubMed: 19158430]

114. Schenck A, et al. The endosomal protein Appl1 mediates Akt substrate specificity and cell survival in vertebrate development. Cell. 2008; 133:486-497. [PubMed: 18455989]

115. Furuya T, et al. Negative regulation of Vps34 by Cdk mediated phosphorylation. Mol Cell. 38:500-511. [PubMed: 20513426]

116. Garcia-Arencibia M, Hochfeld WE, Toh PP, Rubinsztein DC. Autophagy, a guardian against neurodegeneration. Semin Cell Dev Biol. 2010

117. Frost B, Diamond MI. Prion-like mechanisms in neurodegenerative diseases. Nat Rev Neurosci. 2010; 11:155-159. [PubMed: 20029438]

118. Nixon RA. Niemann-Pick Type C disease and Alzheimer's disease: the APP-endosome connection fattens up. Am J Pathol. 2004; 164:757-761. [PubMed: 14982829]

119. Nixon RA. Endosome function and dysfunction in Alzheimer's disease and other neurodegenerative diseases. Neurobiol Aging. 2005; 26:373-382. [PubMed: 15639316]

120. Jick H, Zornberg GL, Jick SS, Seshadri S, Drachman DA. Statins and the risk of dementia. Lancet. 2000; 356:1627-1631. [PubMed: 11089820]

121. Wolozin B, et al. Simvastatin is associated with a reduced incidence of dementia and Parkinson's disease. BMC Med. 2007; 5:20. [PubMed: 17640385]

122. Arvanitakis Z, et al. Statins, incident Alzheimer disease, change in cognitive function, and neuropathology. Neurology. 2008; 70:1795-1802. [PubMed: 18199831]

123. Feldman $\mathrm{HH}$, et al. Randomized controlled trial of atorvastatin in mild to moderate Alzheimer disease: LEADe. Neurology. 2010; 74:956-964. [PubMed: 20200346]

124. Abrahamson EE, Ikonomovic MD, Dixon CE, DeKosky ST. Simvastatin therapy prevents brain trauma-induced increases in beta-amyloid peptide levels. Ann Neurol. 2009; 66:407-414. [PubMed: 19798641]

125. Kandiah N, Feldman HH. Therapeutic potential of statins in Alzheimer's disease. J Neurol Sci. 2009; 283:230-234. [PubMed: 19321181]

126. Durakoglugil MS, Chen Y, White CL, Kavalali ET, Herz J. Reelin signaling antagonizes betaamyloid at the synapse. Proceedings of the National Academy of Sciences of the United States of America. 2009; 106:15938-15943. [PubMed: 19805234]

127. Cole GM, Ma QL, Frautschy SA. Omega-3 fatty acids and dementia. Prostaglandins Leukot Essent Fatty Acids. 2009; 81:213-221. [PubMed: 19523795]

128. Palacios-Pelaez R, Lukiw WJ, Bazan NG. Omega-3 essential Fatty acids modulate initiation and progression of neurodegenerative disease. Mol Neurobiol. 2010; 41:367-374. [PubMed: 20467837]

129. Grimm MO, et al. Docosahexaenoic Acid reduces amyloid \{beta\} production via multiple, pleiotropic mechanism. The Journal of biological chemistry. 2011

130. Bertram L, Tanzi RE. Genome-wide association studies in Alzheimer's disease. Hum Mol Genet. 2009; 18:R137-145. [PubMed: 19808789]

131. Harold D, et al. Genome-wide association study identifies variants at CLU and PICALM associated with Alzheimer's disease. Nat Genet. 2009; 41:1088-1093. [PubMed: 19734902]

132. Lambert JC, et al. Genome-wide association study identifies variants at CLU and CR1 associated with Alzheimer's disease. Nat Genet. 2009; 41:1094-1099. [PubMed: 19734903]

133. Sanders AE, et al. Association of a functional polymorphism in the cholesteryl ester transfer protein (CETP) gene with memory decline and incidence of dementia. JAMA. 2010; 303:150158. [PubMed: 20068209]

134. Wenk MR. The emerging field of lipidomics. Nat Rev Drug Discov. 2005; 4:594-610. [PubMed: 16052242] 
135. Piomelli D, Astarita G, Rapaka R. A neuroscientist's guide to lipidomics. Nat Rev Neurosci. 2007; 8:743-754. [PubMed: 17882252]

136. Han X, Holtzman DM, McKeel DW Jr. Plasmalogen deficiency in early Alzheimer's disease subjects and in animal models: molecular characterization using electrospray ionization mass spectrometry. J Neurochem. 2001; 77:1168-1180. [PubMed: 11359882]

137. Cheng H, Xu J, McKeel DW Jr. Han X. Specificity and potential mechanism of sulfatide deficiency in Alzheimer's disease: an electrospray ionization mass spectrometric study. Cell Mol Biol (Noisy-le-grand). 2003; 49:809-818. [PubMed: 14528918]

138. Cheng H, Zhou Y, Holtzman DM, Han X. Apolipoprotein E mediates sulfatide depletion in animal models of Alzheimer's disease. Neurobiol Aging. 2010; 31:1188-1196. [PubMed: 18762354]

139. Sharman MJ, et al. Profiling brain and plasma lipids in human APOE epsilon2, epsilon3, and epsilon4 knock-in mice using electrospray ionization mass spectrometry. J Alzheimers Dis. 2010; 20:105-111. [PubMed: 20164599]

140. Lingwood D, Simons K. Lipid rafts as a membrane-organizing principle. Science. 2010; 327:4650. [PubMed: 20044567]

141. Lingwood D, Kaiser HJ, Levental I, Simons K. Lipid rafts as functional heterogeneity in cell membranes. Biochem Soc Trans. 2009; 37:955-960. [PubMed: 19754431]

142. Allen JA, Halverson-Tamboli RA, Rasenick MM. Lipid raft microdomains and neurotransmitter signalling. Nat Rev Neurosci. 2007; 8:128-140. [PubMed: 17195035]

143. Jacobson K, Mouritsen OG, Anderson RG. Lipid rafts: at a crossroad between cell biology and physics. Nat Cell Biol. 2007; 9:7-14. [PubMed: 17199125]

144. Ramstedt B, Slotte JP. Sphingolipids and the formation of sterol-enriched ordered membrane domains. Biochim Biophys Acta. 2006; 1758:1945-1956. [PubMed: 16901461]

145. Ramstedt B, Slotte JP. Membrane properties of sphingomyelins. FEBS Lett. 2002; 531:33-37. [PubMed: 12401199]

146. Xu X, London E. The effect of sterol structure on membrane lipid domains reveals how cholesterol can induce lipid domain formation. Biochemistry. 2000; 39:843-849. [PubMed: 10653627]

147. Butterfield DA, et al. In vivo oxidative stress in brain of Alzheimer disease transgenic mice: Requirement for methionine 35 in amyloid beta-peptide of APP. Free Radic Biol Med. 2010; 48:136-144. [PubMed: 19854267]

148. Schneider C, Porter NA, Brash AR. Routes to 4-hydroxynonenal: fundamental issues in the mechanisms of lipid peroxidation. J Biol Chem. 2008; 283:15539-15543. [PubMed: 18285327]

149. Bush AI, Tanzi RE. Therapeutics for Alzheimer's disease based on the metal hypothesis. Neurotherapeutics. 2008; 5:421-432. [PubMed: 18625454] 


\section{TEXT BOX 1: The amyloid cascade hypothesis}

The amyloid cascade hypothesis supports the idea that amyloid $\beta$-peptide $(\mathrm{A} \beta)$ plays a central and even causative role for AD ${ }^{1,2}$. Cleavage of $\beta$-amyloid precursor protein (APP) by BACE1 liberates its soluble ectodomain (sAPP $\beta$ ) into the extracellular space. The resulting cell-associated $\mathrm{COOH}$-terminal fragments, which can be either 99 or 89 amino acids in length (termed "C99" or "C89"), are subjected to intramembrane proteolysis mediated by $\gamma$-secretase, which generates a spectrum of $A \beta$ peptides of varying length at the $\mathrm{COOH}$ terminus as well as the APP intracellular $\mathrm{COOH}$-terminal domain (AICD) ${ }^{1,2}$. The predominant species of $A \beta$ is 40 amino acids long (A $\beta 40$ ), but the less abundant 42 -amino acid variant $(\mathrm{A} \beta 42)$ is more amyloidogenic and is the initial $\mathrm{A} \beta$ species that deposits into amyloid plaques in all forms of $\mathrm{AD}{ }^{1,2}$. Cleavage of APP within the A $\beta$ sequence by $\alpha$-secretase followed by $\gamma$-secretase cleavage, the nonamyloidogenic pathway, results in the production of a shorter, likely innocuous APP fragment (p3), along with the secreted ectodomain (sAPP $\alpha$ ) and AICD ${ }^{1,2}$. Although AD brains typically harbor senile plaques that consist of insoluble aggregates of $A \beta$, different assemblies of $A \beta$, including fibrils as well as soluble dimers, trimers and dodecamers, may differentially contribute to AD pathogenesis at various stages of this disorder ${ }^{1,2}$. Importantly, elevation of soluble $\mathrm{A} \beta$ oligomers strongly correlates with cognitive decline, consistent with the synaptotoxic properties exhibited by these peptides in various systems ${ }^{1,2}$. In sum, the modern amyloid cascade hypothesis takes into consideration the various assembly states of $A \beta$.

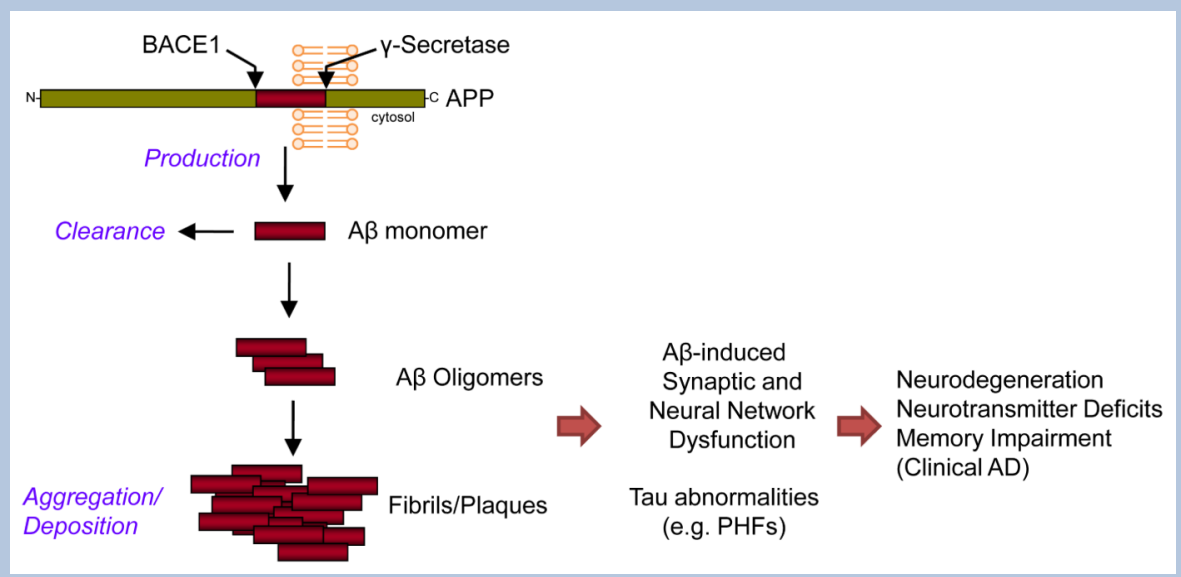

Text Box 1 Figure The amyloid cascade hypothesis. The cartoon illustrates the amyloidogenic proteolytic processing of APP leading to the production of $A \beta$ and the role of this peptide in various assembly forms in the pathophysiological progression of AD. 


\section{TEXT BOX 2: Lipid rafts}

Lipid rafts are heterogenous, cholesterol- and sphingolipid-rich membrane microdomains that mediate compartmentalized cellular processes by clustering receptors and signaling molecules ${ }^{140-143}$. In addition to cholesterol and sphingolipids, these dynamic lipidprotein assemblies are enriched in saturated glycerophospholipids and protein molecules with a high inherent affinity for ordered lipid domains. Raft lipids are believed to be held together by relatively weak covalent bonds, establishing a dynamic equilibrium of raft and non-raft regions within the plasma membrane ${ }^{140}$. The sphingolipids interact laterally through van der Waals interactions and extensive hydrogen bonding between the sphingosine backbones and between the sugar head groups ${ }^{144}$. Moreover, the majority of sphingolipids have saturated, and therefore unkinked, acyl chains that allow tighter packing of laterally associated lipids and a higher gel-liquid phase transition temperature ${ }^{145}$. These interactions lead to segregation of sphingolipid-rich domains from their glycerophospholipid-rich surroundings. The degree of lateral association is further increased by the presence of cholesterol. The 3- $\beta$-hydroxyl group of cholesterol hydrogen bonds with the ceramide group of sphingolipids, while its planar sterol ring interacts with the saturated acyl chain ${ }^{144,146}$. Growing evidence indicates that the amyloidogenic processing of APP occurs in lipid rafts, largely because functionally active pools of BACE1 and $\gamma$-secretase are present in these microdomains, alongside a pool of APP. A popular idea is that decreasing the association of these proteins with lipid rafts may be beneficial in AD, although the extent to which this approach would interfere with their physiological functions must be considered. 


\section{TEXT BOX 3: The old theory of lipid peroxidation in AD}

Oxidative stress is a hallmark of many degenerative disorders. The brain is particularly vulnerable to this phenomenon due to high oxygen consumption, enrichment in polyunsaturated fatty acids (PUFAs) and high levels in redox metal ions ${ }^{147}$. Lipid peroxidation products (LPPs) have been found in brain, cerebrospinal fluid and plasma from patients with $\mathrm{AD}^{147}$. Primary substrates for lipid peroxidation are PUFAs and include $\omega-6$ fatty acids (e.g., linoleic, arachidonic acid) as well as $\omega-3$ fatty acids (e.g., DHA). Reactive oxygen species (ROS) are responsible for starting the chain by the production of an unstable lipid radical which is converted to a lipid peroxyl radical, leading to the peroxidation of other fatty acids ('propagation'). This chain reaction stops ('termination') when two radicals react to produce a non-radical species or due to antioxidants (e.g., vitamin $\mathrm{C}$ and $\mathrm{E}$ ) and enzymes of the superoxide dismutase, catalase, and peroxidase families ${ }^{148}$. Oxidized PUFAs are further degraded to toxic products, such as 4-hydroxy-2-nonenal (HNE), acrolein and other short-chain aldehydes. Importantly, $A \beta$ has been shown to cause oxidative stress through its interaction with transition metal ions, such as $\mathrm{Cu}^{2+}$ and $\mathrm{Zn}^{2+}$, which are enriched in senile plaques ${ }^{149}$. $\mathrm{A} \beta$ can reduce these metal ions, thus producing hydrogen peroxide. During this process, A $\beta$ becomes oxidized, thereby leading to the crosslinking of some of its residues' sidechains and the formation of aggregate-prone adducts. Alternatively, hydrogen peroxide can be generated catalytically from $\mathrm{Cu}^{2+}$ - or $\mathrm{Zn}^{2+}$-bound $\mathrm{A} \beta$ using other electron donors (e.g., PUFAs, cholesterol), a process leading to the generation of toxic LPPs, such as oxysterol and HNE. Finally, A $\beta$ itself can be crosslinked by HNE. Key challenges in the field are to understand the role of LPP accumulation in the progression of AD-associated manifestations. 


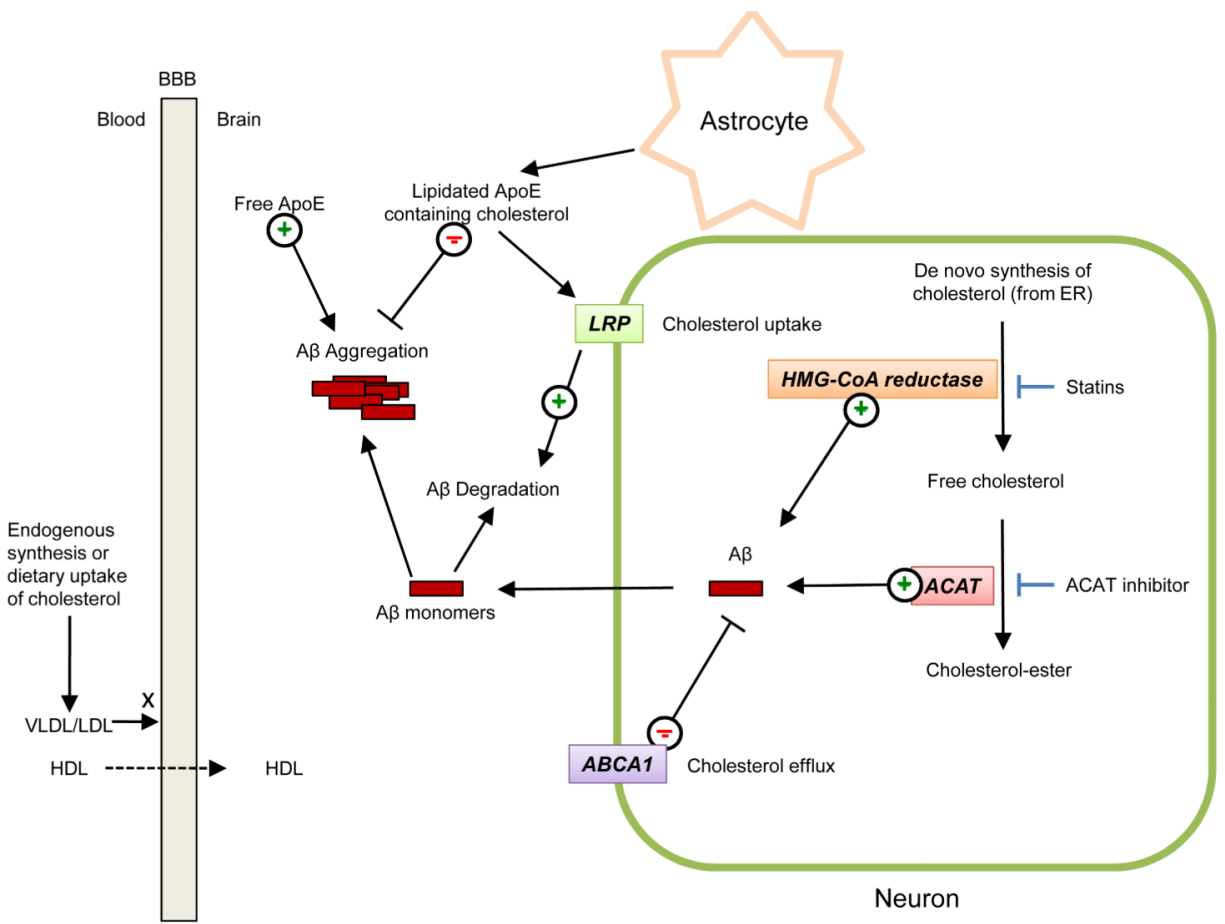

Figure 1. Contribution of cholesterol and apolipoprotein $\mathbf{E}$ metabolism to biogenesis, degradation and assembly of amyloid $\beta$-peptide

Cholesterol in the brain is mainly derived from de novo synthesis from the endoplasmic reticulum. Small amounts of cholesterol can also be delivered to the brain from the periphery, via high density liproproteins (HDL), which can cross the blood-brain-barrier (BBB) unlike larger lipoproteins, such as low density lipoproteins (LDL) and very low density lipoproteins (VLDL). Hydroxymethyl glutaryl-coenzyme A (HMG-CoA) reductase mediates the rate-limiting step in de novo cholesterol biosynthesis. Excess free cholesterol is converted into cholesterol-ester by acyl-coenzyme A:cholesterol acyltransferase (ACAT). Inhibition of HMG-CoA reductase by statins leads to decreased levels of $A \beta$ in animal models and ACAT inhibition has been also shown to reduce $A \beta$ levels by a mechanism that remains as yet poorly defined. ApoE-containing HDL-like particles inhibit the aggregation of $A \beta$, while free ApoE has been shown to promote $A \beta$ aggregation. LDL receptor-related protein (LRP) serves as a neuronal receptor for astrocyte-produced ApoE-containing lipid particles, thus mediating their internalization into neurons where they are broken down. ApoE-containing HDL-like particles inhibit the aggregation of $\mathrm{A} \beta$, while free ApoE has been shown to promote $\mathrm{A} \beta$ aggregation in vitro. $\mathrm{ABAC} 1$, a regulator of cholesterol efflux, has been also shown to modulate $A \beta$ levels in neurons. For simplicity, $A \beta$ is drawn as freefloating in the cytoplasm, although it is produced in the lumen of neuronal organelles of the late secretory and endolysosomal systems, from where it can be secreted. 

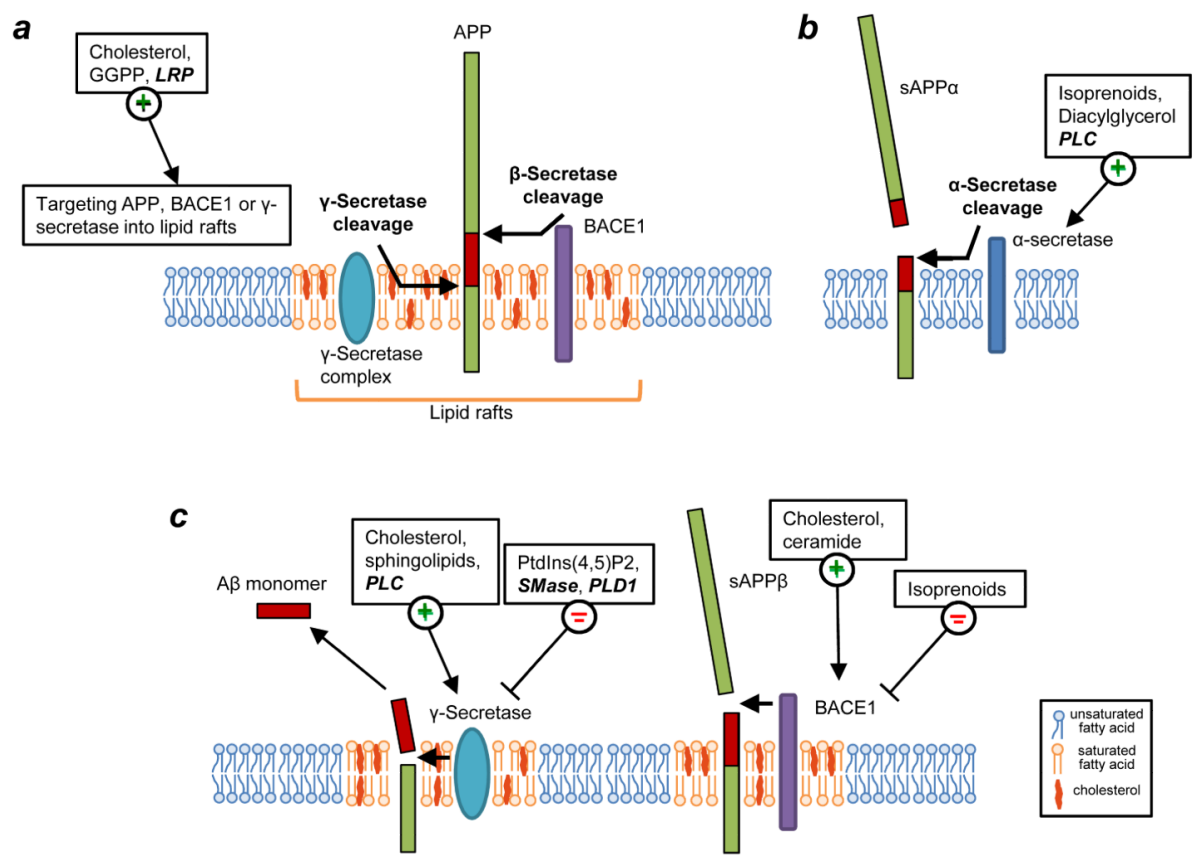

Figure 2. Modulation of proteolytic processing of $\beta$-amyloid precursor protein (APP) by lipids (a) The $\beta$-amyloid precursor protein (APP) undergoes amyloidogenic processing mediated either by $\beta$ - and $\gamma$-secretases to yield amyloid $\beta$-peptide $(\mathrm{A} \beta)$ (purple rectangles). Amyloidogenic processing of APP largely occurs in lipid rafts. Cholesterol and LRP, an ApoE receptor, promote the localization of BACE1 to lipid rafts. GGPP (a short chain isoprenoid) has been shown to promote the association of the $\gamma$-secretase complex with lipid rafts. Several lipids (shown in bold text) and lipid metabolizing proteins (italicized bold text) influence APP processing through a variety of mechanisms. (b) APP is also subjected in neurons to a non-amyloidogenic pathway mediated by $\alpha$-secretase. Localization of APP to non-lipid raft compartments favors processing by $\alpha$-secretase. Isoprenoids, diaglycerol and phospholipase C (PLC) have been shown to promote the non-amyloidogenic pathway. (c) The relative abundance or absence of the lipids listed on the figure directly influences the activity of BACE1 or $\gamma$-secretase. Increased levels of cholesterol or ceramide enhance the activity of BACE1. Cholesterol and sphingolipids are positive modulators of $\gamma$-secretase activity while SMase and PLD1 have been identified as negative modulators of $\gamma$-secretase activity. PLC-mediated hydrolysis of PtdIns $(4,5) \mathrm{P}_{2}$ promotes amyloidogenesis by stimulating $\gamma$-secretase activity and PtdIns $(4,5) \mathrm{P}_{2}$ has been shown to directly inhibit $\gamma$ secretase activity. 


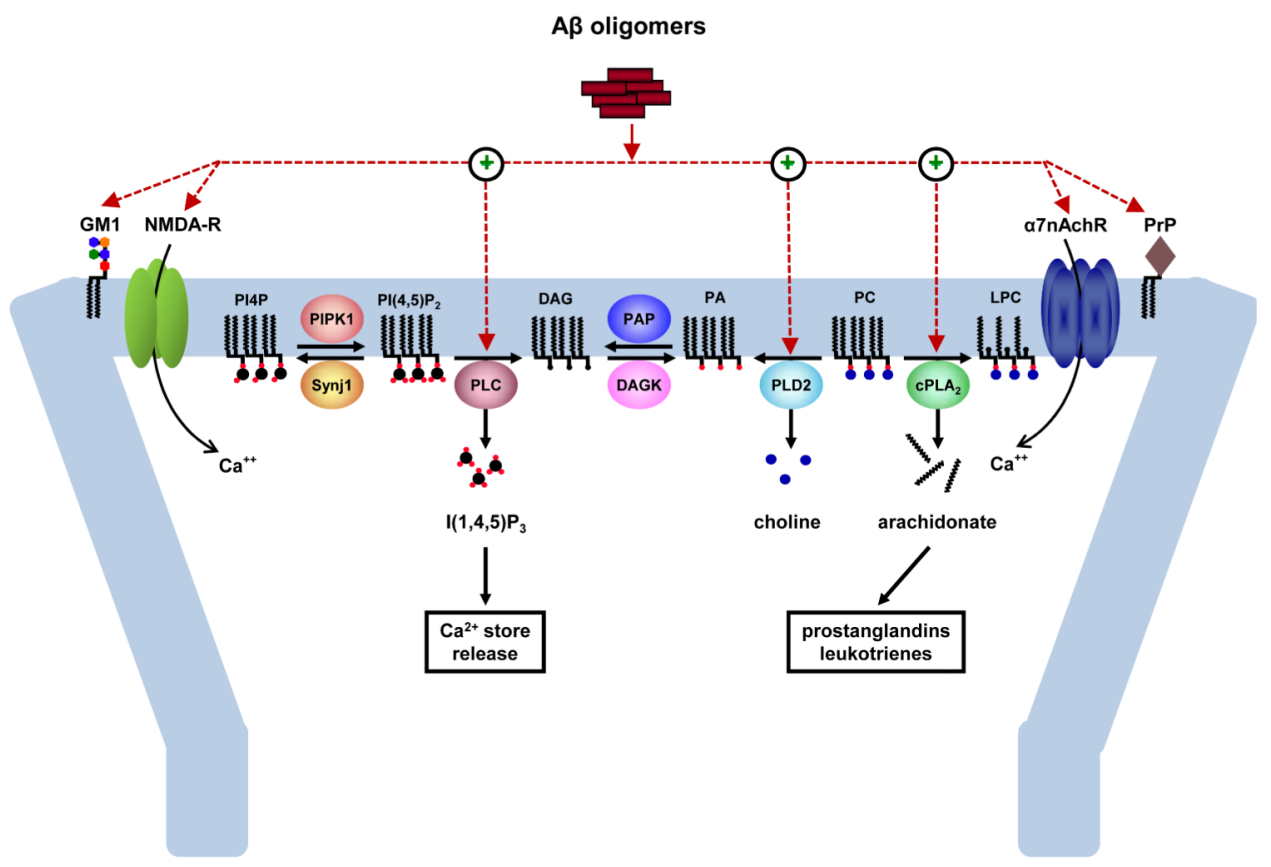

Figure 3. Role of lipids in A $\beta$-induced alterations in neuronal signaling and synaptic plasticity $\mathrm{A} \beta$ oligomers interact with a number of cell surface molecules, such as gangliosides (e.g., GM1) and $\mathrm{Ca}^{2+}$-permeable neurotransmitter receptor-channels [e.g., the NMDA and $\alpha 7$ nicotinic acetylcholine receptors $(\alpha 7 \mathrm{nAchR})]$, to influence neuronal activity and synaptic function in neurons. Some of these receptor-channels, such as the NMDA receptor, are critical for synaptic plasticity and are involved in learning and memory. A variety of A $\beta$ oligomer species have been shown to potently alter synaptic function, in part by enhancing the activity of phospholipase C (PLC), cytosolic phospholipase A2 (cPLA2) and phospholipase D2 (PLD2). PLC hydrolyzes phosphatidylinositol-4,5-bisphosphate $\left[\operatorname{PtdIns}(4,5) \mathrm{P}_{2}\right]$ to diacylglycerol (DAG) and inositol-1,4,5-trisphosphate $\left[\operatorname{Ins}(1,4,5) \mathrm{P}_{3}\right]$. cPLA2 hydrolyzes phosphatidylcholine (PC) to arachidonate and lysophosphatidylcholine (LPC). PLD2 hydrolyzes PC to phosphatidic acid (PA) and choline. The crosstalk and functional hierarchy among these phospholipases remain to be determined, although a common denominator for their activation appears to be elevation of intracellular $\mathrm{Ca}^{2+}$. Decreased dephosphorylation of PtdIns $(4,5) \mathrm{P}_{2}$ to phosphatidylinositol-4-phosphate (PtdIns4P) resulting from the heterozygous deletion of phosphoinositide phosphatase synaptojanin 1 (Synj1) confers protection against the synaptotoxic action of A $\beta$ oligomers, indicating that phospholipid metabolism can directly influence the susceptibility of neurons to A $\beta$. PAP, phosphatidic acid phosphatase; DAGK, diacylglycerol kinase. 